\section{Long-term treatment of Bartter's syndrome with captopril}

Hypokalaemia is the dominant feature and the main target of treatment in Bartter's syndrome. Other abnormalities include an overstimulated renin-aldosterone system, angiotensin resistance, hyperprostaglandinuria, increased plasma bradykinin and urinary kallikrein excretion (but decreased urinary kinin excretion), and a chloridelosing nephropathy. The cause of this condition has proved to be elusive, and the syndrome has therefore been characterised as the biological counterpart of an integrated electronic circuit. ${ }^{1}$ Drugs directed at various elements of this circuit (for example, beta-blockers, aldosterone antagonists, prostaglandin inhibitors, and amiloride) have all been applied with some degree of success, albeit often only temporary and partial. ${ }^{2}$ We report on the long-term administration of the converting-enzyme inhibitor captopril in one patient.

\section{Case report}

A 35-year-old man with familial Bartter's syndrome had previously been treated with spironolactone $(200 \mathrm{mg}$ daily). During this treatment, which had had to be stopped because of headache and nausea, the serum potassium concentration had risen from 2.8 to $3.8 \mathrm{mmol}(\mathrm{mEq}) / 1$. He was admitted to hospital. Before captopril was started the serum potassium concentration had returned to $2.5 \mathrm{mmol} / 1$. Plasma renin activity was raised, and the extracellular fluid volume (volume of distribution of bromine-82) lay below the estimated range (figure). Blood pressure, which fell from $120 / 75 \mathrm{~mm} \mathrm{Hg}$

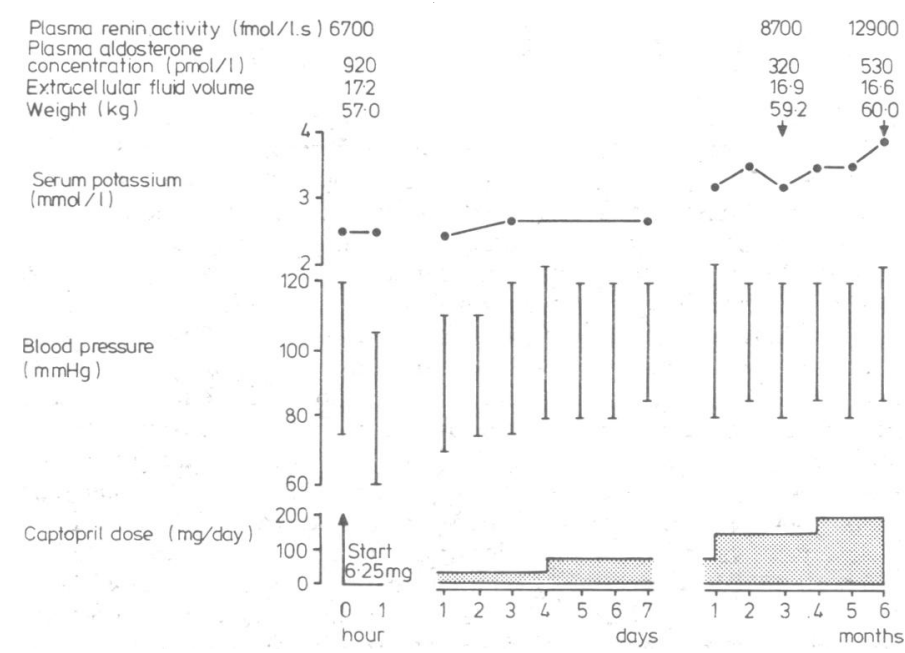

Plasma renin activity (normal 150-1000 fmol/1/s (70-467 ng/100 ml/h)), plasma aldosterone concentration (normal 100-1000 pmol/1 (3.6-36 ng/100 ml)), extracellular fluid volume (estimated normal value $17 \cdot 2-19 \cdot 61$ ), body weight, serum potassium concentration, and blood pressure during chronic treatment with captopril.

Conversion: SI to traditional units-Plasma renin activity: $1 \mathrm{fmol} / 1 / \mathrm{s} \approx$ $0.5 \mathrm{ng} / 100 \mathrm{ml}$. Plasma aldosterone $1 \mathrm{pmol} / 1 \approx 0.04 \mathrm{ng} / 100 \mathrm{ml}$. Serum potassium: $1 \mathrm{mmol} / \mathrm{l}=1 \mathrm{mEq} / 1$.

to a minimum of $105 / 60 \mathrm{~mm} \mathrm{Hg}$ after an initial dose of $6.25 \mathrm{mg}$ captopril, slowly returned to the pretreatment level on the third day at a dose of $37.5 \mathrm{mg}$ daily. Further increase in the dosage to $75 \mathrm{mg}$ daily did not affect his blood pressure, and he was discharged on the seventh day. Serum potassium concentration rose and reached a maximum of $3.9 \mathrm{mmol} / 1$ in the sixth month, when the daily dose of captopril was $200 \mathrm{mg}$. At this stage plasma renin activity was about double and plasma aldosterone concentration half the initial value, and his sensitivity to exogenous angiotensin II appeared normal $(20 \mathrm{~mm} \mathrm{Hg}$ rise in diastolic blood pressure during infusion of $7 \mathrm{ng} / \mathrm{kg} / \mathrm{min}$ ). He felt considerably better and his body weight increased, although repeated measurements of extracellular fluid volume showed no change.

\section{Comment}

A decrease in plasma aldosterone concentration and increase in serum potassium concentration are expected after blockade of angiotensin II formation in a patient with Bartter's syndrome. The fall in blood pressure after the initial dose of captopril was also expected, but the gradual return to pretreatment values while the drug was continued was not. Previous reports on captopril in Bartter's syndrome have mentioned only acute effects ${ }^{3}$ or the effect during administration of the drug for three days. ${ }^{4}$ In the latter study captopril seems to have been stopped because of prolonged depression of blood pressure.

The normalisation of blood pressure during prolonged treatment in our patient suggests that some vasodilatory factor had changed. Two such factors, bradykinin and prostaglandins, are raised in Bartter's syndrome. Overproduction of bradykinin has even been suggested to be the primary cause of the syndrome. Since degradation of this peptide is inhibited by captopril a prolonged reduction of blood pressure would have been a more likely consequence. A decreased prostaglandin concentration would offer an alternative explanation, but in acute experiments captopril has been reported to increase prostaglandin $\mathrm{E}$ concentrations in patients with hypertension, the hypotensive effect being closely related to this increase. ${ }^{5}$ It remains possible, however, that after prolonged administration of captopril in Bartter's syndrome prostaglandin E concentrations return towards normal, resulting in a gradual increase in blood pressure. The increase in serum potassium concentration might also contribute to the depression of prostaglandin $\mathrm{E}$ production.

Other explanations for the secondary rise in blood pressure towards the pretreatment level could be a rise in extracellular fluid volume and non-compliance with the drug. Both seem unlikely, because repeated measurements of extracellular fluid volume showed no increase and the sustained rise of serum potassium concentration and the normal response to exogenous angiotensin II exclude non-compliance. Further detailed studies are needed to elucidate this. Meanwhile, captopril remains a useful treatment in patients with Bartter's syndrome and an investigational tool.

This study was supported by the Dutch Kidney Foundation.

${ }^{1}$ Bourke E, Delaney V. Bartter's syndrome-a dilemma of cause and effect. Nephron $1981 ; 27: 177-86$

${ }^{2}$ Simatupang TA, Radó JP, Boer P, Geyskes GG, Vos J, Mees EJD. Pharmacologic studies in Bartter's syndrome: opposite effects of treatment with antikaliuretic and antiprostaglandin drugs. Int $f$ Clin Pharmacol 1978;16:14-8.

${ }^{3}$ Mizuno K, Yamazaki M, Fukuchi S. Hypotensive response to angiotensin I-converting enzyme inhibitor in Bartter's syndrome. $N$ Engl f Med 1979;300:1057.

4 Aurell M, Rudin A. Effects of captopril in Bartter's syndrome. $N$ Engl f Med $1981 ; 304: 1609$.

5 Moore TJ, Crantz FR, Hollenberg NK, et al. Contribution of prostaglandins to the antihypertensive action of Captopril in essential hypertension. Hypertension $1981 ; 3: 168-73$.

(Accepted 29 fune 1982)

Department of Nephrology and Hypertension, University Hospital, Catharijnesingel 101, NL-3511 GV Utrecht, The Netherlands

RONALD J HENE, MD, internist

HENDRIK A KOOMANS, MD, internist

PETER BOER, PHD, biochemist

EVERT J DORHOUT MEES, MD, professor of nephrology

\section{Laboratory-acquired shigellosis}

Pike elicited circumstantial evidence that many laboratory-associated infections get overlooked while a small proportion of those noted are reported. ${ }^{1} \mathrm{He}$ found a report of only one such case of bacterial dysentery (1929), which ended in death. We describe another case, in which the patient survived.

\section{Case report}

A technician in a country laboratory dropped on the bench a rectal swab, received during a national quality assurance exercise, on pulling it out of the Stuart transport medium. She felt droplets falling on her gown and face. After replacing the swab she removed the gown and washed her hands and face with water, then with Hibiclens (chlorhexidine), and finally with Savlon (chlorhexidine plus cetrimide). She then wiped the bench with methylated spirit. About 54 hours later she developed fever, malaise, and dysentery that caused her to see a doctor a week later. Her condition worsened, and she was admitted to hospital three days later and prescribed sulphonamide after a stool sample was taken. She improved rapidly. The culture yielded Shigella flexneri, which was confirmed as having the same serotype and antibiogram (susceptible to sulphonamide) as the strain that 
had been isolated from the survey specimen in heavy growth. Stool cultures taken when she returned to work the next week proved negative.

\section{Comment}

$S$ flexneri has the smallest infecting dose of enteropathogenic bacteria-namely, about 200 viable cells for healthy volunteers-so that infections in laboratory workers are not uncommon. ${ }^{2}$ Interestingly, laboratory-acquired infections of all kinds have in general occurred most often in trained bench workers in diagnostic services, and spills and sprays have equalled hypodermic needles as the commonest mode. ${ }^{1}$

In this case gargling with copious water followed by thorough washing of the face and hands with soap and water might have been more effective than the brief exposures to antiseptics. The State Health Commission recommends a phenolic disinfectant for laboratory fixtures but offers no guidance on measures for people who become contaminated. ${ }^{3}$

1 Pike RM. Laboratory-associated infections: incidence, fatalities, causes and prevention. Ann Rev Microbiol 1979 ;33:41-66.

${ }^{2}$ Hornick RB. Shigellosis. In: Hoeprich PD, ed. Infectious diseases: a modern treatise of infectious processes. 2nd ed. New York: Harper and Row, 1977:549-54.

3 Health Commission of New South Wales. Code of safe practice in clinical laboratories. Sydney, NSW: Health Commission of NSW, 1980.

\section{(Accepted 4 June 1982)}

Clinical Microbiology Department, Royal Newcastle Hospital, Australia 2300

H K GHOSH, PHD, FRCPA, director

\section{Fatal pulmonary fibrosis occurring during treatment with cyclophosphamide}

Pulmonary fibrosis is an uncommon complication of drug treatment and has been reported in association with many cytotoxic drugs. ${ }^{1} \mathrm{We}$ describe two patients who developed pulmonary fibrosis while receiving cyclophosphamide for glomerulonephritis.

\section{Case reports}

Case 1-A 58-year-old man was admitted to hospital with rigors, anorexia, increasing dyspnoea, and a non-productive cough. For seven weeks he had been taking $100 \mathrm{mg}$ cyclophosphamide and $30 \mathrm{mg}$ prednisolone daily for a rapidly progressive glomerulonephritis, and his renal function had been improving (serum creatinine concentration $311 \mu \mathrm{mol} / 1 ; 3.5 \mathrm{mg} / 100 \mathrm{ml}$ ) Examination showed fever, a tachycardia of $100 / \mathrm{min}$, crepitations at both lung bases, and a left-sided pleural rub. Radiography showed left-sided basal shadowing. Intravenous cefuroxime $750 \mathrm{mg}$ twice daily was given after specimens had been taken for culture. One week later he became acutely unwell, with cyanosis, tachypnoea, intercostal indrawing, a trachea tug, and increase in intensity of the pleural rub. Blood gas analysis yielded $\mathrm{PCO}_{2} 2 \mathrm{kPa}(15 \mathrm{~mm} \mathrm{Hg})$ and $\mathrm{Po}_{2} 4.7 \mathrm{kPa}(35 \mathrm{~mm} \mathrm{Hg})$ on air. Chest radiography showed mid-zone and basal shadowing. Cyclophosphamide and cefuroxime were stopped and gentamicin, flucloxacillin, and co-trimoxazole introduced after bronchoscopy. Ventilatory support was required, initially with intermittent positive-pressure ventilation and later with positive end-expiratory pressure, between $60 \%$ and $100 \%$ oxygen being needed to maintain his $\mathrm{PO}_{2}$ within the normal range. Ten days after admission an open-lung biopsy was performed without complication. Despite further treatment with high-dose steroids and co-trimoxazole, he continued to deteriorate and died in respiratory failure after a gastrointestinal haemorrhage 20 days after presentation.

Case 2-A 29-year-old man with a refractory nephrotic syndrome secondary to a diffuse proliferative glomerulonephritis (serum creatinine concentration $186 \mu \mathrm{mol} / 1 ; 2 \cdot 1 \mathrm{mg} / 100 \mathrm{ml}$ ) had been taking cyclophosphamide $200 \mathrm{mg}$ daily and prednisolone $10 \mathrm{mg}$ thrice daily for four months. He was admitted with a cough, rigors, and fever. There were signs suggestive of a left-sided bronchopneumonia. Radiologically this developed into a generalised micronodular pattern associated with a clinical deterioration over six days. Cyclophosphamide was stopped and intravenous cefuroxime $750 \mathrm{mg}$ twice daily begun. Initially blood gas analysis on air yielded $\mathrm{PCO}_{\text {g }}$ $2.3 \mathrm{kPa}\left(17 \mathrm{~mm} \mathrm{Hg}\right.$ ) and $\mathrm{Po}_{2} 3.3 \mathrm{kPa}(25 \mathrm{~mm} \mathrm{Hg})$. After bronchoscopy and transbronchial biopsy doxycycline $100 \mathrm{mg}$ daily, co-trimoxazole 2 tablets twice daily, and antituberculous treatment with rifampicin $600 \mathrm{mg}$ and isoniazid $150 \mathrm{mg}$ were introduced empirically and $70 \%$ oxygen via an Inspiron mask was required. Again further ventilatory support was needed, during which time an open-lung biopsy was performed, but respiratory failure progressed, with increasing hypoxia and decreasing lung compliance, leading to death 21 days after initial presentation.

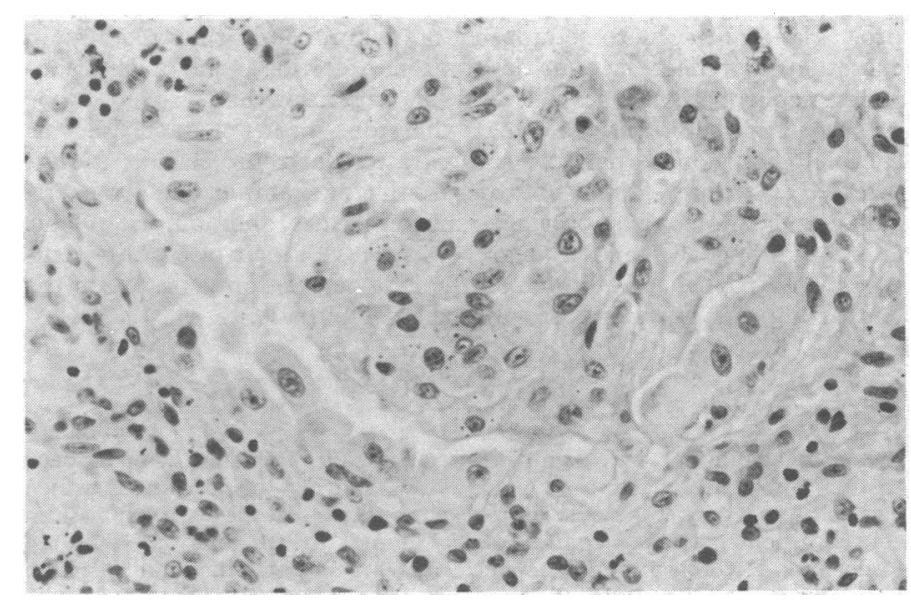

Alveolus partly lined by bizarre epithelial cells and containing ingrowth of granulation tissue. Alveolar sputum contained heavy chronic inflammatory infiltrate. (Haematoxylin and eosin. Original magnification $\times 250$.)

\section{Comment}

In both patients no evidence of an infective agent was obtained. Cultures of sputum, urine, and blood all gave negative results, as did serological studies for legionellae, aspergillus, and candida. Viral titres remained insignificant. Biopsy material obtained in both cases at bronchoscopy and open-lung biopsy showed widespread severe interstitial fibrosis, less pronounced in case 2 . There were newly formed reticulin fibres, organising and organised intra-alveolar exudates, and florid regenerative proliferation of alveolar epithelial cells, which were large, occasionally multinucleated, and often bizarre. A moderate, rather focal interstitial infiltrate of lymphocytes and plasma cells was present (fig). There was no evidence of malignancy, and staining for infective organisms, including Pneumocystis carinii, gave negative results. Necropsy in both cases showed diffuse pulmonary consolidation, histologically the same as that obtained at biopsy and considered to be similar to the fibrosis associated with busulphan treatment. ${ }^{2}$ In the absence of any evidence of infection we believe that the progressive fibrosis was secondary to cyclophosphamide treatment. This reaction has been reported with low total dosage of cyclophosphamide after short courses ${ }^{3}$ but to our knowledge not in association with the treatment of renal disease. Only three cases of pulmonary fibrosis in association with cyclophosphamide have been reported to the Committee on the Safety of Medicines. World wide, eight cases have been documented. Resolution, however, often followed withdrawal of the drug. ${ }^{34}$ The mechanism of the reaction remains unsolved.

We thank Mr M Elliott for performing the open-lung biopsies.

1 Brewis RAL. Textbook of adverse drug reactions. Ch 8. London: Oxford University Press, 1981 .

2 Batist G, Andreus JL. Pulmonary toxicity of antineoplastic drugs. FAMA $1981 ; 246: 1449-53$.

3 Spector JI, Zimbler H, Ross JS. Early onset cyclophosphamide-induced interstitial pneumonitis. $\mathcal{F} A M A$ 1979;242:2852-4.

4 Patel AR, Shah PC, Rhee HL, et al. Cyclophosphamide therapy and interstitial pulmonary fibrosis. Cancer 1976;38:1542-9.

(Accepted 18 fune 1982)

Royal Victoria Infirmary, Newcastle upon Tyne NE1 4LP

D A BURKE, MB, BS, senior house officer

J C STODDART, MD, FFA RCS, consultant in charge, intensive therapy unit M K WARD, MB, MRCP, consultant physician

Newcastle General Hospital, Newcastle upon Tyne NE4 6BE C G B SIMPSON, MRCPATH, lecturer in pathology 